\title{
Determinant Powers of Socioeconomic Factors and Their Interactive Impacts on Particulate Matter Pollution in North China
}

\author{
Xiangxue Zhang ${ }^{1,2}$, Yue $\operatorname{Lin}^{3}{ }^{(1)}$, Changxiu Cheng ${ }^{1,2,4, *}$ and Junming $\mathrm{Li}^{5, *}$ \\ 1 Key Laboratory of Environmental Change and Natural Disaster, Ministry of Education, \\ Beijing Normal University, Beijing 100875, China; zxx@lreis.ac.cn \\ 2 State Key Laboratory of Earth Surface Processes and Resource Ecology, \\ Beijing Normal University, Beijing 100875, China \\ 3 Department of Geography, The Ohio State University, Columbus, OH 43210, USA; \\ lin.3326@buckeyemail.osu.edu \\ 4 National Tibetan Plateau Data Center, Beijing 100101, China \\ 5 School of Statistics, Shanxi University of Finance and Economics, Taiyuan 030006, China \\ * Correspondence: chengcx@bnu.edu.cn (C.C.); lijm@sxufe.edu.cn (J.L.)
}

Citation: Zhang, X.; Lin, Y.;

Cheng, C.; Li, J. Determinant Powers of Socioeconomic Factors and Their Interactive Impacts on Particulate Matter Pollution in North China. Int. J. Environ. Res. Public Health 2021, 18, 6261. https://doi.org/10.3390/ ijerph18126261

Academic Editor: Paul B. Tchounwou

Received: 10 May 2021

Accepted: 8 June 2021

Published: 9 June 2021

Publisher's Note: MDPI stays neutral with regard to jurisdictional claims in published maps and institutional affiliations.

Copyright: (c) 2021 by the authors. Licensee MDPI, Basel, Switzerland. This article is an open access article distributed under the terms and conditions of the Creative Commons Attribution (CC BY) license (https:/ / creativecommons.org/licenses/by/ $4.0 /)$

\begin{abstract}
Severe air pollution has significantly impacted climate and human health worldwide In this study, global and local Moran's I was used to examine the spatial autocorrelation of $\mathrm{PM}_{2.5}$ pollution in North China from 2000-2017, using data obtained from Atmospheric Composition Analysis Group of Dalhousie University. The determinant powers and their interactive effects of socioeconomic factors on this pollutant are then quantified using a non-linear model, GeoDetector. Our experiments show that between 2000 and 2017, $\mathrm{PM}_{2.5}$ pollution globally increased and exhibited a significant positive global and local autocorrelation. The greatest factor affecting $\mathrm{PM}_{2.5}$ pollution was population density. Population density, road density, and urbanization showed a tendency to first increase and then decrease, while the number of industries and industrial output revealed a tendency to increase continuously. From a long-term perspective, the interactive effects of road density and industrial output, road density, and the number of industries were amongst the highest. These findings can be used to develop the effective policy to reduce $\mathrm{PM}_{2.5}$ pollution, such as, due to the significant spatial autocorrelation between regions, the government should pay attention to the importance of regional joint management of $\mathrm{PM}_{2.5}$ pollution.
\end{abstract}

Keywords: GeoDetector; long-term variations; $\mathrm{PM}_{2.5}$ concentrations; spatial autocorrelation; spatial heterogeneity

\section{Introduction}

In recent years, problems related to air pollution have become increasingly severe worldwide and air pollution had a severe impact on climatic, economic development, and human health [1-4]. Of the atmospheric pollutants, particulate matter with an aerodynamic diameter of less than $2.5 \mu \mathrm{m}\left(\mathrm{PM}_{2.5}\right)$ is the most harmful pollutant and has received increased attention recently [5-7]. $\mathrm{PM}_{2.5}$ can severely impact environmental conditions, reducing atmospheric visibility and including climate change [8]. Even more seriously, previous studies have demonstrated that severe $\mathrm{PM}_{2.5}$ pollution can cause pathological reactions in respiratory and cardiovascular systems and greatly increase mortality [9-11]. Due to rapid urbanization, these problems have become more prominent in China $[12,13]$ and may not only lead to the migration of large populations but also to the increased consumption of energy [14]. Therefore, $\mathrm{PM}_{2.5}$ and related issues have received widespread research attention worldwide.

In early studies, more attention was paid to explore the driving factors of $\mathrm{PM}_{2.5}$ pollution, it has become increasingly apparent that socioeconomic and other pollutant factors would 
impact the accumulation and diffusion of $\mathrm{PM}_{2.5}$ worldwide [15,16]. Puentes et al. took Santiago, the capital of Chile, as an example, and used a bivariate regression prediction model to estimate the PM levels related to $\mathrm{PM}_{2.5}$ and $\mathrm{PM}_{10}$ at the same time. The results showed that the two pollutants have a strong relationship [17]. Due to the city being the spatial carrier of the above sources, one changes in response to the changes of others.

With the rapid urbanization, more research has involved socioeconomic factors such as population density [18], coal consumption [16], industrial structures [19], built-up areas [20], per capita gross domestic product (GDP) [21], and road density [16], as a means of determining which human activities contribute most to $\mathrm{PM}_{2.5}$ concentrations. For example, Cavieres et al. showed that there is severe air pollution in Santiago of Chile, which is mainly caused by anthropogenic activities that use combustion and may further exert adverse effects on human health [22]. Wu et al. constructed panel data models within an environmental Kuznets curve framework to investigate the correlations between per capita per capita gross domestic product (GDP) and $\mathrm{PM}_{2.5}$ concentrations; their result was an inverted U-shaped curve [21]. By employing a structural equation model, Jiang et al. demonstrated that $\mathrm{PM}_{2.5}$ concentrations in China were related to city size and the activities of both industries and residents [23]. Based on nonparametric additive regression models, $\mathrm{Xu}$ et al. found that, in China, there was an inverted-U shaped pattern between $\mathrm{PM}_{2.5}$ concentrations and economic activity, urbanization, number of private vehicles, and coal consumption [24].

Moreover, to detect and quantify the dominant driving factors of $\mathrm{PM}_{2.5}$ pollution, research studies have typically used linear models, such as spatial Durbin analyses [25], Bayesian hierarchical analyses [26], traditional econometrics models [27], panel data models [21], spatial lag/error models [28], geographic weighted regressions [29] and clustering methods [30]. For example, Du et al. indicated that $\mathrm{PM}_{2.5}$ concentrations were strongly correlated to GDP and built-up area [25]. Using a Pearson's correlation analysis, Han et al. demonstrated that population size, built-up area, and the proportion of secondary industries had significant positive impacts on $\mathrm{PM}_{2.5}$ [20]. Moreover, Zhang et al. found a positive correlation between $\mathrm{PM}_{2.5}$ concentrations and population size using spatial interpolation [31]. These are just a few examples of the growing knowledge that socioeconomic factors have important impacts on $\mathrm{PM}_{2.5}$ pollution using a series of linear models.

However, it remains unclear which, among these potential factors, is dominant in terms of $\mathrm{PM}_{2.5}$ pollution in North China. Notably, the potential interactive impacts of these factors on $\mathrm{PM}_{2.5}$ pollution and whether or not either their determinant powers or interactions will remain the same over time are also currently unknown. Moreover, traditional methods are flawed in quantifying the interaction of factors that affect $\mathrm{PM}_{2.5}$. For example, the interaction of two factors can take many forms of coupling in reality, but in traditional regression methods, it is usually the product of two factors, and their ability to explain the heterogeneity of spatial stratification is poor. Therefore, in contrast to the various linear methods used in previous studies, non-linear models, such as GeoDetector, have been applied in this study to both quantify the determinant powers of socioeconomic factors and their interactive effects on $\mathrm{PM}_{2.5}$ concentrations in North China. That is, the aims of this study were to: (1) examine the evolution of hot/cold spots (i.e., regions becoming more/less polluted) in North China from 2000-2017, (2) identify the dominant factor(s) impacting $\mathrm{PM}_{2.5}$ concentrations each year, and (3) quantify the determinant powers and their interactive effects of socioeconomic factors on $\mathrm{PM}_{2.5}$ pollution over time using GeoDetector software for the measurement and attribution of stratified heterogeneity. The rest of this study is designed as follows: data sources and models applied in this study are introduced in Section 2, while the analysis results and key findings are mainly elaborated in Section 3. Section 4 then provides a discussion of the findings, and finally, Section 5 presents the study conclusions and policy recommendations. 


\section{Materials and Methods}

\subsection{Study Area}

North China comprises the provinces of Hebei, Henan, and Shandong, which consist of 48 cities, including Beijing and Tianjin (Figure 1). Compared with other regions in China, the urban population in this region suffers more severe $\mathrm{PM}_{2.5}$ pollution due to the presence of a large number of coal-based industries [32]. According to the Ministry of Environmental Protection of China, the air quality in 2015 of Baoding, Xingtai, Hengshui, Tangshan, Zhengzhou, Jinan, Handan, Shijiazhuang, Langfang, and Shenyang were the worst 10 cities, all these cities are located in the North China region, aside from Shenyang. Furthermore, the heating of most cities in this region places a great burden on the atmospheric environment, especially in winter. The area of North China is $543,000 \mathrm{~km}^{2}$; with a population of approximately 320 million, it is one of the most densely populated regions in China. In recent years, the accelerated growth of urbanization and industrialization in this region, means that energy consumption is enormous, and it has generated a large amount of atmospheric pollution, significantly impacting the atmospheric environment; this cannot be ignored. Therefore, the effective prevention and management of $\mathrm{PM}_{2.5}$ pollution in the area is crucial.

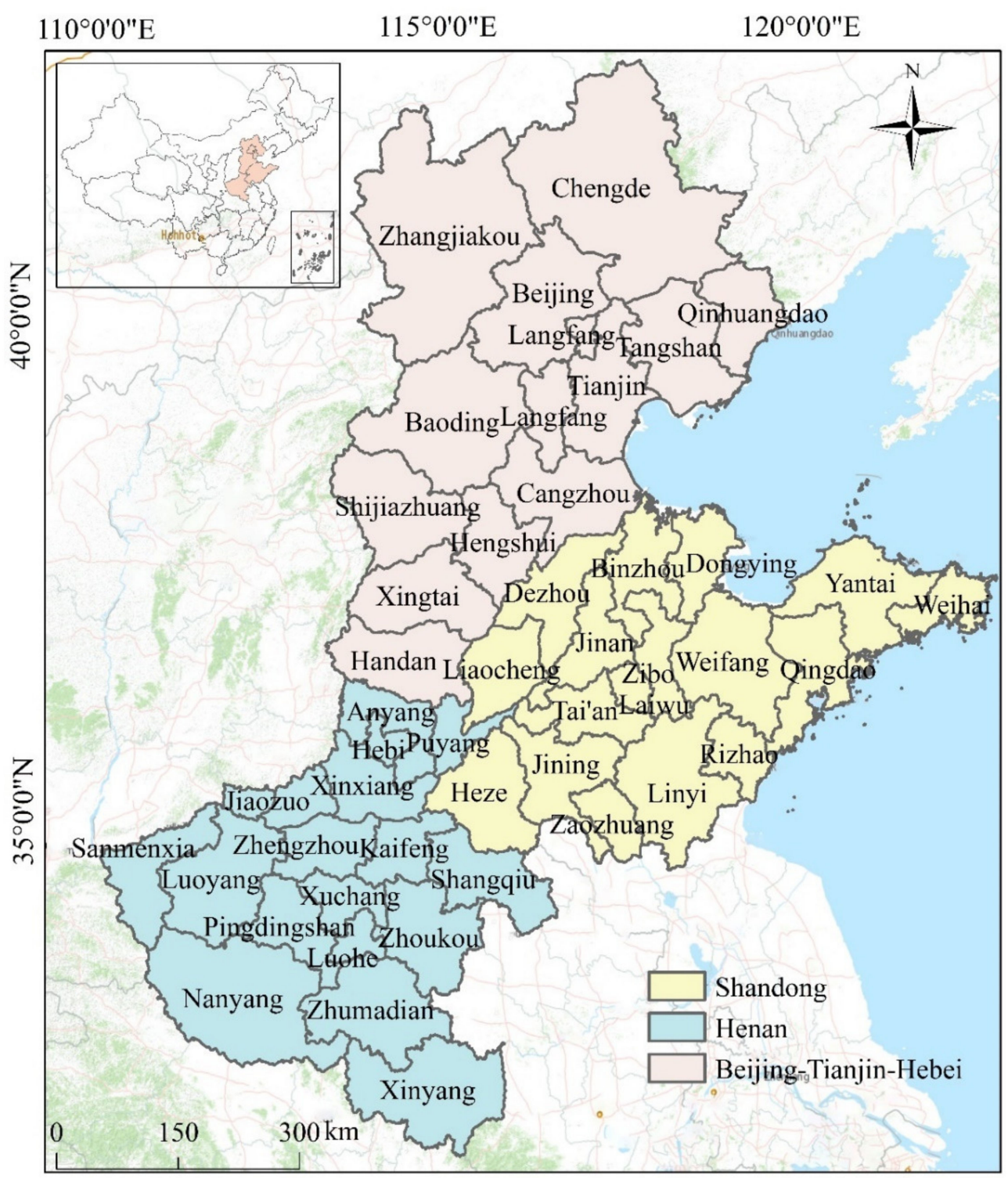

Figure 1. Spatial location of the study area. 


\subsection{Data Sources}

The $\mathrm{PM}_{2.5}$ concentration data from 2000-2017 analyzed in this study were collected from the Atmospheric Composition Analysis Group of Dalhousie University [33], which has a spatial resolution of $0.1^{\circ} \times 0.1^{\circ}$. This dataset has great accuracy as it has been corrected with global station-based observation values based on the geographically weighted regression model, with an $\mathrm{R}^{2}$ value of 0.817 [34] and has been used in many studies [16,34,35]. Using the regional statistical tools in ArcGIS 10.3, the mean $\mathrm{PM}_{2.5}$ concentration data for each year in each city of the study area from 2000 to 2017 were then extracted (Figure 2).

Table 1. Descriptions of the indicators for socioeconomic factors.

\begin{tabular}{|c|c|c|c|}
\hline Variables & Definitions & Units & Data Sources \\
\hline Population & Population density (PD) & $10^{4}$ person $/ \mathrm{km}^{2}$ & China City Statistical Yearbook \\
\hline \multirow{2}{*}{ Industry } & Industrial output (IO) & $10^{6}$ Yuan $/ \mathrm{km}^{2}$ & (http://data.cnki.net/NewHome/index) \\
\hline & Number of industries (NI) & 1 & (accessed on 16 May 2020) \\
\hline Traffic & Road density (RD) & $\mathrm{Km} / \mathrm{km}^{2}$ & $\begin{array}{l}\text { Open Street Map (https: / / www.openstreetmap.org) } \\
\text { (accessed on } 20 \text { May 2020) }\end{array}$ \\
\hline Urbanization & $\begin{array}{l}\text { Proportion of non-agricultural } \\
\text { population (UR) }\end{array}$ & $\%$ & $\begin{array}{c}\text { China City Statistical Yearbook } \\
\text { (http:/ / data.cnki.net/NewHome/index) } \\
\text { (accessed on 16 May 2020) }\end{array}$ \\
\hline Energy use & Fossil fuel combustion (FC) & $10^{4} \mathrm{~m}^{3}$ & $\begin{array}{l}\text { China City Statistical Yearbook } \\
\text { (http:// data.cnki.net/NewHome/index) } \\
\text { (accessed on 16 May 2020) }\end{array}$ \\
\hline
\end{tabular}

\subsection{Statistical Analyses}

A global Moran's I model was used to reveal whether or not the $\mathrm{PM}_{2.5}$ concentrations of a given region impacted its neighboring regions within the study period. Local indicators of spatial association (LISA) statistics were used to explore the hot/cold (high/low) spots of $\mathrm{PM}_{2.5}$ concentrations. The GeoDetector (www.geodetector.cn, accessed on 18 June 2020) model was then used to quantify the determinant powers and interactive effects of socioeconomic factors on $\mathrm{PM}_{2.5}$ concentrations.

First, in this study, a global Moran's I model [37] was employed to test and quantify the spatial autocorrelation of $\mathrm{PM}_{2.5}$ concentrations from 2000-2017. The formula for this model is defined as follows:

$$
I=\frac{n}{\sum_{i=1}^{n} \sum_{j=1}^{n} w_{i j}} \frac{\sum_{i=1}^{n} \sum_{j=1}^{n} w_{i j}\left(y_{i}-\bar{y}\right)\left(y_{j}-\bar{y}\right)}{\sum_{i=1}^{n}\left(y_{i}-\bar{y}\right)^{2}},
$$

where the $I$ value ranges from -1 to 1 and the larger the absolute value of $I$ is, the stronger the autocorrelation becomes; $n$ is the number of cities; $w_{i j}$ is the spatial connection matrix, the value of which is 1 if polygons $i$ and $j$ are adjacent; and $y_{i}, y_{j}$, and $\bar{y}$ are the city-level mean values in cities $i, j$, and the study area, respectively. The statistic $I$ was obtained in this study using 999 Monte Carlo permutations, and the significance of the $I$ value was measured by the $p$-value (at the 5\% significant level), which performed in GeoDa 1.16 software and was download from http:/ / geodacenter.github.io/download.html (accessed on 18 June 2020), and the features of computer used is 64 bit.

Second, local indicators of spatial association (LISA) was used to analyze global spatial autocorrelation analysis, but it cannot present local differences in each city. Therefore, to detect the hot/cold spots of the study area, LISA statistics were used [38] according to the following formula:

$$
I_{i}=\frac{n\left(y_{i}-\bar{y}\right) \sum_{j=1}^{n} w_{i j}\left(y_{j}-\bar{y}\right)}{\sum_{i=1}^{n}\left(y_{i}-\bar{y}\right)^{2}},
$$

where $y_{i}, y_{j}, \bar{y}$, and $w_{i j}$ are the same as in Equation (1). If $I_{i}>0$, a positive correlation existed between city $i$ and the surrounding cities with similar levels of $\mathrm{PM}_{2.5}$ pollution. This facilitated the observation of spatial clusters (i.e., hot spots (high-high; $\mathrm{HH}$ ) or cold 
spots (low-low; LL)). Conversely, a negative correlation was observed, it indicated the presence of spatial outliers (i.e., high-low, HL; low-high, LH).

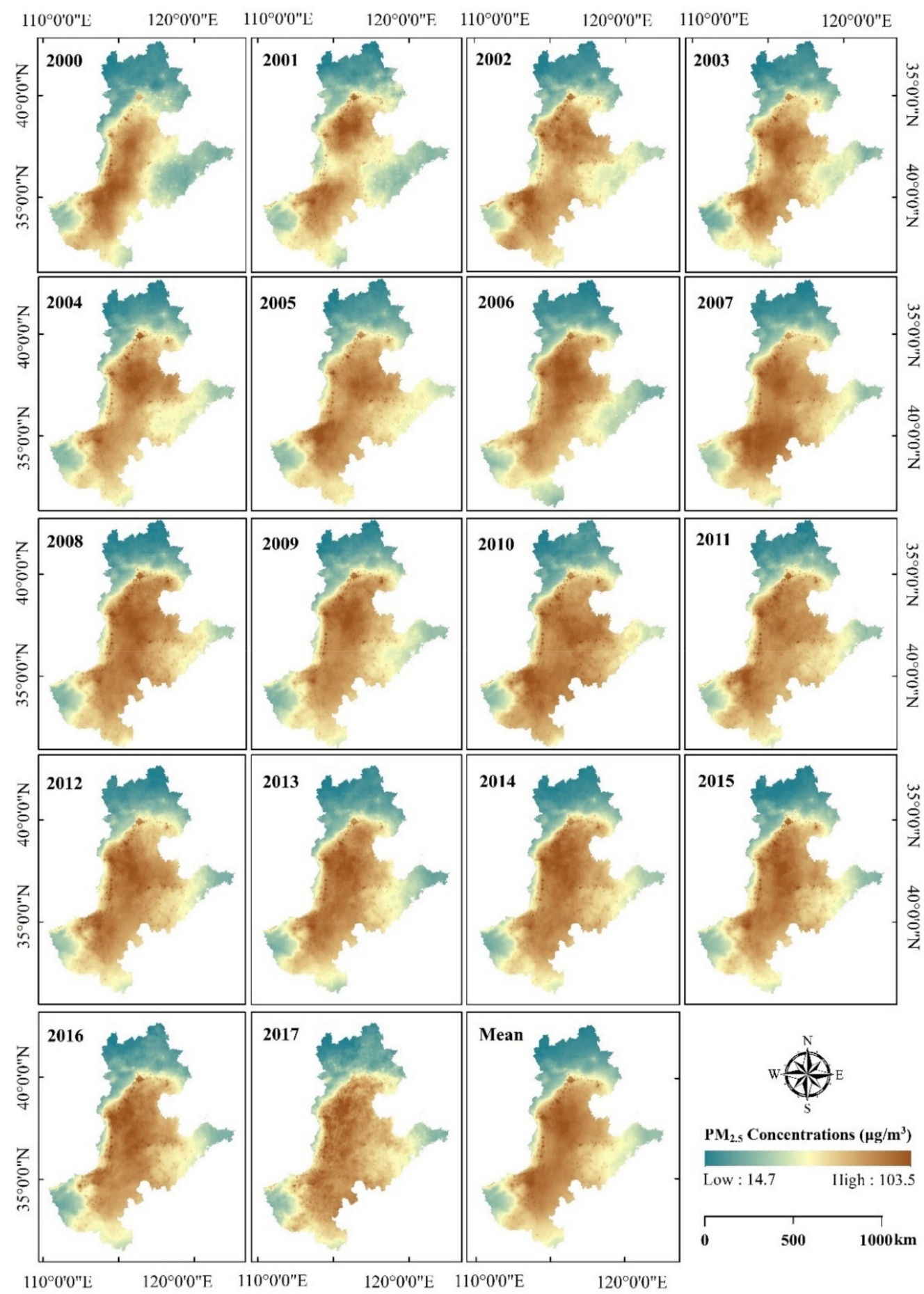

Figure 2. Spatiotemporal evolution of the annual mean $\mathrm{PM}_{2.5}$ concentrations from 2000-2017 in North China (data source: http:/ / fizz.phys.dal.ca/ atmos/martin/ accessed on 20 May 2020). Based on the results of previous studies, the explanatory variables used in this study were: population density (PD), industrial output (IO), number of industries (NI), road density (RD), fossil fuel combustion (FC), and proportion of the non-agricultural population (UR) (Table 1). The UR is a traditional and commonly used proxy to represent urbanization. Additionally, the road data calculated in this study were obtained from Open Street Map [36], which maps urban roads and multi-segment highways. The line density tool in ArcGIS was then used to calculate RD in each city of the study area from 2000 to 2017. 
All of these analyses were implemented in GeoDa 1.16 software and download from http:/ / geodacenter.github.io/download.html (accessed on 18 June 2020), and the features of computer used is 64 bit.

Third, GeoDetector was used to quantify the determinant powers of socioeconomic factors and their interactive effects on $\mathrm{PM}_{2.5}$ concentrations. It was assumed that if a given factor $(\mathrm{X})$ determined the response variable $(\mathrm{Y})$, the response variable would present a similar spatial distribution to that of the factor [39-41]. It has been employed in the fields of geology, environment, health, disasters, and other many fields [42-44], as indicated in the following formula:

$$
q=1-\frac{\sum_{h=1}^{L} N_{h} \sigma_{h}^{2}}{N \sigma^{2}},
$$

where the $q$ value ranged from 0 to 1 , indicating the determinant power of the factor. The larger the value of $q$, the stronger the determinant power of the factor. Here, $N$ and $N_{h}$ represent the number of cities in the entire study area and stratum $h$, respectively; $\sigma^{2}$ and $\sigma_{h}{ }^{2}$ denote the variance of all cities in the study and stratum $h$ and the study area was stratified into $\mathrm{L}$ strata, denoted by $h=1,2, \ldots, L$.

The interactive effects of different factors $(\mathrm{Xs})$ can also be quantified by the GeoDetector, which investigates whether or not the interactions of factors $(X 1 \cap X 2)$ weakens or enhances the influence on $\mathrm{Y}$ by comparing the values of $q(\mathrm{X} 1), q(\mathrm{X} 2)$, and $q(\mathrm{X} 1 \cap \mathrm{X} 2)$ (Figure 3$)$.
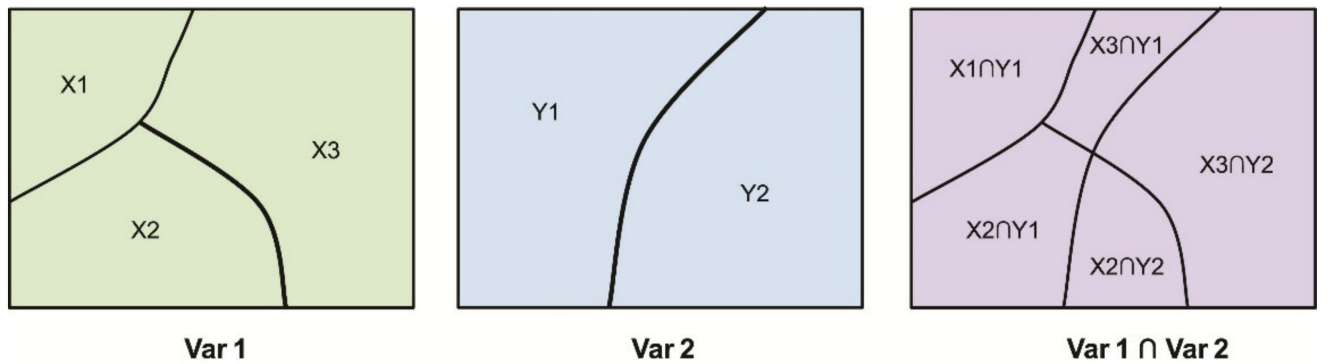

Figure 3. Principle of interactive effects.

It is noteworthy that one of the advantages of GeoDetector is that it does not make linear assumptions for factors, such that the problem of multicollinearity is precluded. Therefore, adding or deleting variables will not impact the results. The GeoDetector tool was download from www.geodetector.cn (accessed on 10 July 2020) and implementation in Excel 2019 (Microsoft, Redmond, WA, USA) (the features of computer used is 64 bit).

\section{Results}

\subsection{Spatiotemporal Analyses}

The global Moran's I values of $\mathrm{PM}_{2.5}$ concentrations from 2000-2017 were all positive and statistically significant at an $\alpha$-level $=1 \%(p<0.01)$ (Table 2). Notably, the values of $I$ all exceeded 0.60 , with a maximum value of 0.75 and a minimum of 0.61 . This not only indicates that $\mathrm{PM}_{2.5}$ concentrations were significantly spatially autocorrelated in the study area (i.e., cities with high(low) $\mathrm{PM}_{2.5}$ concentrations tended to cluster near cities with high(low) values), but also that these autocorrelations remained high during the study period. Only the results at four time points are shown; however, they are representative of the full data (Figure S1). Most of the points shown in Figure S1 are found in the first and third quadrants, indicating that during the selected period, most cities exhibited significant and positive spatial autocorrelations. 
Table 2. Global Moran's I of $\mathrm{PM}_{2.5}$ concentrations from 2000-2017.

\begin{tabular}{cccc}
\hline Year & Moran's $\boldsymbol{I}$ & Year & Moran's I \\
\hline 2000 & 0.75 & 2009 & 0.61 \\
2001 & 0.66 & 2010 & 0.64 \\
2002 & 0.67 & 2011 & 0.65 \\
2003 & 0.68 & 2012 & 0.71 \\
2004 & 0.62 & 2013 & 0.70 \\
2005 & 0.67 & 2014 & 0.63 \\
2006 & 0.66 & 2015 & 0.67 \\
2007 & 0.72 & 2016 & 0.67 \\
2008 & 0.61 & 2017 & 0.67 \\
\hline
\end{tabular}

The local Moran's I value was used to identify the hot and cold spots of the $\mathrm{PM}_{2.5}$ concentrations in North China. Only the results at five time points, which are representative of the results, are shown here (Figure 4). There were no outliers (high-low or low-high) in the study area, meaning that no areas tended to aggregate with areas with different $\mathrm{PM}_{2.5}$ pollution concentrations.
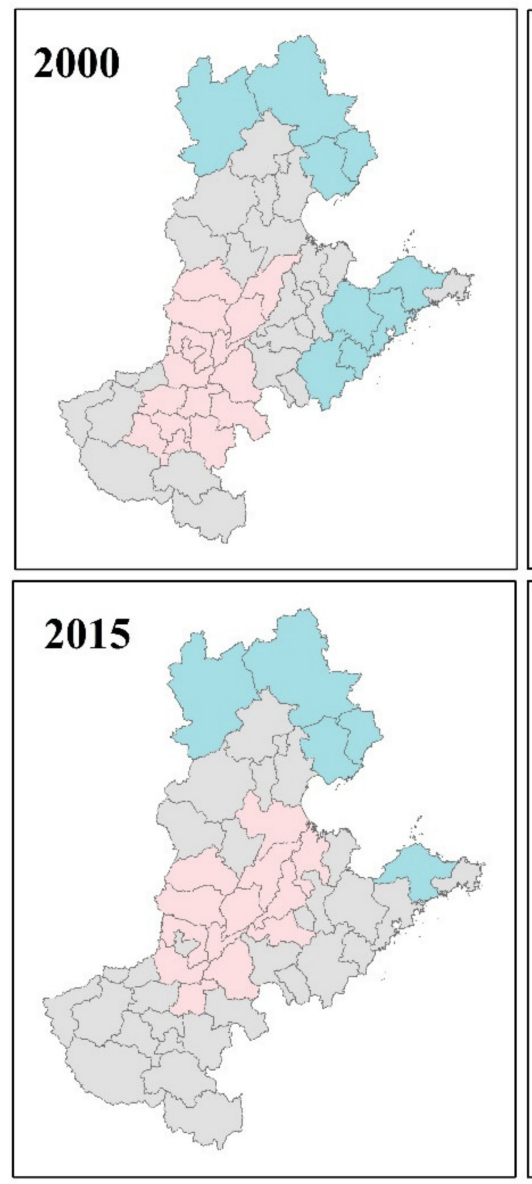
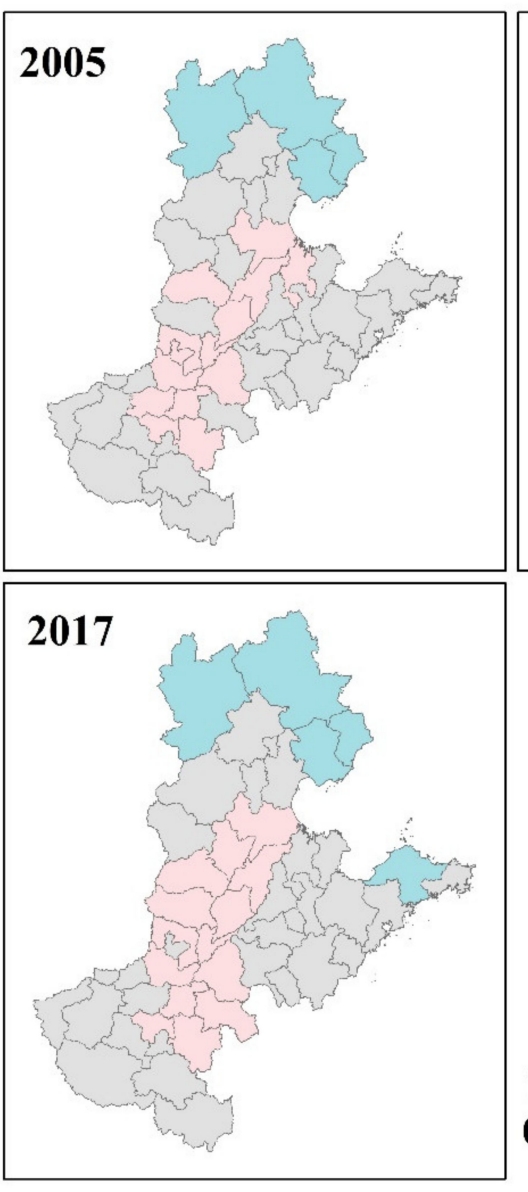
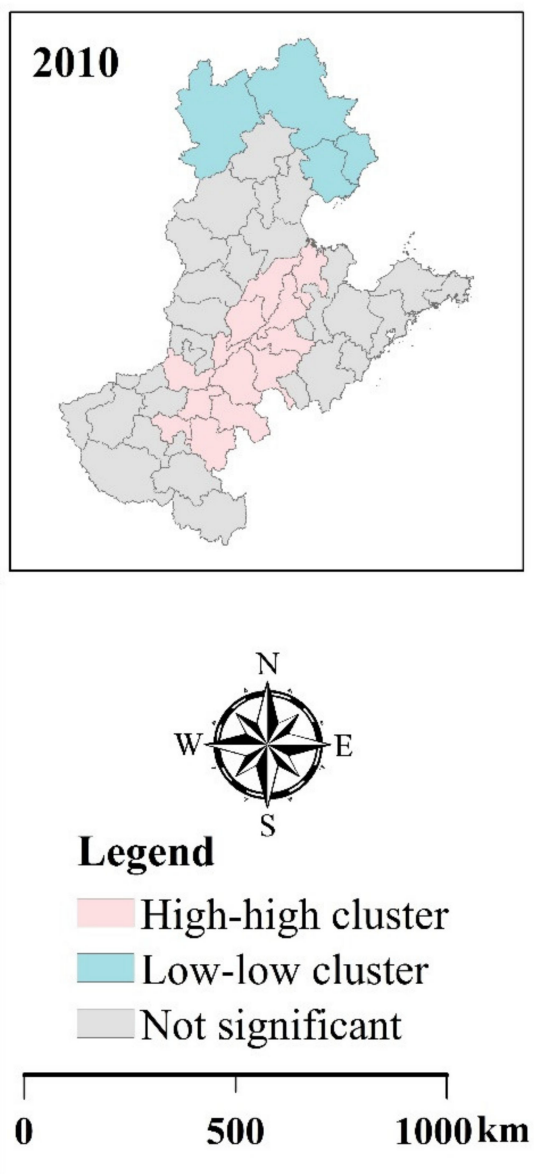

Figure 4. Local Moran's I scatterplots for 2000, 2005, 2010, 2015, and 2017 (data source: http:/ / fizz.phys.dal.ca/ atmos / martin/) (accessed on 15 March 2020).

Spatially, the risk of $\mathrm{PM}_{2.5}$ pollution was relatively high in southeastern Hebei, northern Henan, and western Shandong, while it was relatively low in northern Hebei and eastern Shandong. The frequency of clusters between 2000 and 2017 indicates that Xinxiang, Kaifeng, Dezhou, Xingtai, and Heze are mostly represented by HH clusters each year ( $\geq 16$ out of 18), while Qinhuangdao and Chengde are represented by LL clusters each year 
(Figure S2). In general, stable and high concentrations of $\mathrm{PM}_{2.5}$ clusters were mainly found in southeastern Hebei, northern Henan, and western Shandong.

Temporally, the mean annual value of $\mathrm{PM}_{2.5}$ for each province was extracted to capture its temporal evolution, which showed an upward trend (Figure 5). Both temporal variations and regional differences were observed. Regionally, relatively higher $\mathrm{PM}_{2.5}$ concentrations were recorded in Tianjin and Henan from 2000-2007. In Beijing, it has been always low. As for temporal variation, there are also significant regional differences. For example, the annual mean $\mathrm{PM}_{2.5}$ concentrations in 2000 were 28.24, 42.30, 42.80, 60.59, and $38.48 \mu \mathrm{g} / \mathrm{m}^{3}$ in Beijing, Tianjin, Hebei, Henan, and Shandong, respectively, in which the $\mathrm{PM}_{2.5}$ concentrations in Tianjin, Hebei, and Henan were more than $40 \mu \mathrm{g} / \mathrm{m}^{3}$. Before 2006, $\mathrm{PM}_{2.5}$ concentrations in Beijing, Tianjin, and Hebei all showed obviously increasing trends, with peak values of $58.47,84.66$, and $73.50 \mu \mathrm{g} / \mathrm{m}^{3}$, respectively. However, slightly declining trends were observed between 2007 and 2012. In Henan and Shandong, $\mathrm{PM}_{2.5}$ concentrations also showed primarily increasing trends before 2007, reaching maxima of 84.59 and $73.13 \mu \mathrm{g} / \mathrm{m}^{3}$, followed by a nearly continuous decline from 2007 to 2012 . Interannual fluctuations have been observed since values peaked in 2013 in Beijing, Tianjin, Hebei, Henan, and Shandong.

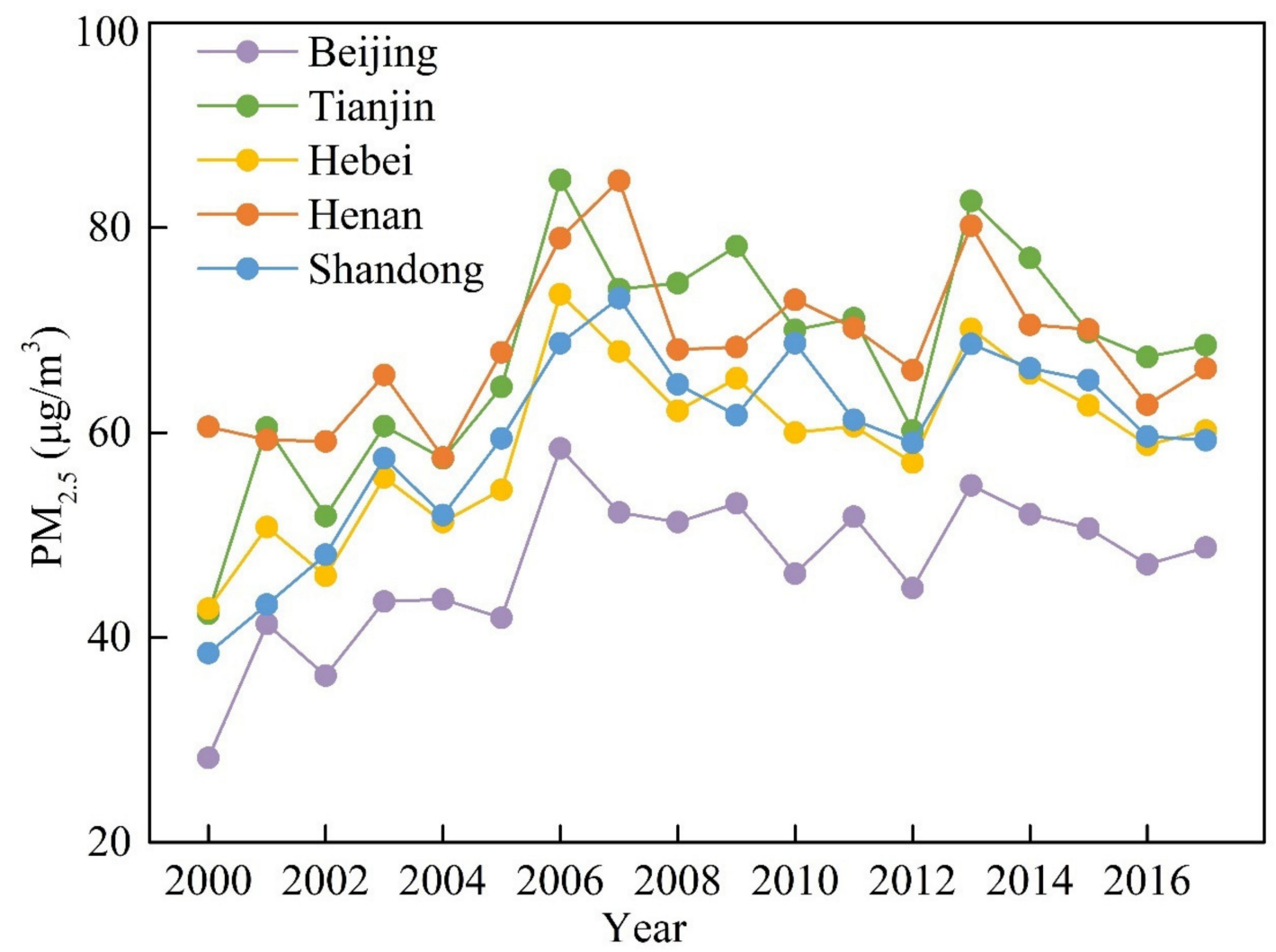

Figure 5. Temporal variations of $\mathrm{PM}_{2.5}$ concentrations from 2000-2017 (data source: http:/ / fizz.phys.dal.ca/ atmos / martin/) (accessed on 15 March 2020).

\subsection{Impact Factors}

The determinant powers ( $q$ values) of the impact factors from 2000-2017 were quantified using GeoDetector (Table 3). Among the five selected factors, PD showed the greatest determinant power for $\mathrm{PM}_{2.5}$ concentrations $(q=0.67)$, followed by IO $(q=0.60)$, NI $(q=0.56), \mathrm{RD}(q=0.53), \mathrm{FC}(q=0.36)$, and UR $(q=0.32)$. The $q$ values presented here are the results for 2017. Of the selected factors, PD exhibited a remarkably dominant effect on $\mathrm{PM}_{2.5}$ concentrations, as demonstrated by its $q$ values, which ranged from 0.27 to 0.67 between 2000 and 2017 (Table 3), which was consistent with the results of other studies, for example, Wang et al. demonstrated that PD had a critical effect, reflected in the accu- 
mulation of $\mathrm{PM}_{2.5}$ by region [18]; similar, Ding et al. showed that PD had the remarkable impact on $\mathrm{PM}_{2.5}$ concentrations [45].

Table 3. The $q$ values of each influence factor from 2000 to 2017.

\begin{tabular}{ccccccc}
\hline Time & PD & IO & NI & RD & UR & FC \\
\hline 2000 & 0.27 & 0.42 & 0.29 & 0.29 & 0.19 & 0.17 \\
2001 & 0.45 & 0.45 & 0.26 & 0.32 & 0.28 & 0.24 \\
2002 & 0.52 & 0.55 & 0.40 & 0.48 & 0.37 & 0.21 \\
2003 & 0.55 & 0.42 & 0.41 & 0.46 & 0.45 & 0.29 \\
2004 & 0.50 & 0.46 & 0.47 & 0.50 & 0.41 & 0.33 \\
2005 & 0.61 & 0.50 & 0.32 & 0.54 & 0.34 & 0.41 \\
2006 & 0.61 & 0.55 & 0.34 & 0.46 & 0.27 & 0.30 \\
2007 & 0.64 & 0.56 & 0.26 & 0.53 & 0.39 & 0.32 \\
2008 & 0.67 & 0.57 & 0.33 & 0.60 & 0.47 & 0.32 \\
2009 & 0.66 & 0.52 & 0.31 & 0.49 & 0.36 & 0.20 \\
2010 & 0.62 & 0.51 & 0.55 & 0.65 & 0.38 & 0.19 \\
2011 & 0.64 & 0.58 & 0.50 & 0.58 & 0.42 & 0.18 \\
2012 & 0.60 & 0.60 & 0.44 & 0.55 & 0.42 & 0.45 \\
2013 & 0.65 & 0.47 & 0.39 & 0.50 & 0.27 & 0.34 \\
2014 & 0.66 & 0.55 & 0.55 & 0.56 & 0.46 & 0.19 \\
2015 & 0.61 & 0.47 & 0.54 & 0.54 & 0.26 & 0.25 \\
2016 & 0.63 & 0.58 & 0.41 & 0.54 & 0.30 & 0.18 \\
2017 & 0.67 & 0.60 & 0.56 & 0.53 & 0.32 & 0.36 \\
\hline
\end{tabular}

The $q$ values of RD indicated that traffic conditions also had an increasing impact on $\mathrm{PM}_{2.5}$ pollution. The $q$ values for $\mathrm{RD}$ (Table 3) ranged from 0.29 to 0.65 , indicating that it accounted for between $29 \%$ and $65 \%$ of $\mathrm{PM}_{2.5}$ concentrations. The factors, IO and $\mathrm{NI}$, generated $q$ values from 0.42 to 0.60 and from 0.26 to 0.56 , respectively, denoting an increasing and significant determinant power of industrial activities on $\mathrm{PM}_{2.5}$ pollution. It is generally believed that industrial growth, as represented by IO and NI, has a nonnegligible impact on the degradation of the environment (Table 3). The $q$ values of UR revealed that the influence of urbanization on $\mathrm{PM}_{2.5}$ pollution was increasing and nonnegligible, ranging from 0.19 to 0.47 , indicating that urbanization accounted for between 19 to $47 \%$ of annual mean $\mathrm{PM}_{2.5}$ concentrations. The $q$ values of FC showed that the influence of fossil fuel combustion on $\mathrm{PM}_{2.5}$ pollution was increasing and non-negligible, ranging from 0.17 to 0.45 , indicating that fossil fuel combustion accounted for between 17 to $45 \%$ of annual mean $\mathrm{PM}_{2.5}$ concentrations (Table 3).

Furthermore, the scatter plots for the selected periods display the $q$ values with quadratic polynomials to fit the trend lines, as well as the labeled $R^{2}$ values with which to explore the changing patterns of these driving factors (Figure 6). PD, RD, UR, and FC all showed a tendency to first increase and then decrease from 2000-2017. Both NI and IO showed increasing trends in the long-term, indicating that industrial activities have an increasing influence on $\mathrm{PM}_{2.5}$ pollution (Figure 6).

Moreover, in total, fifteen pairs of interactions among the five studied variables from 2000-2017 were calculated using the GeoDetector (Figure 7). It was found that the interactive effects of two random factors were greater than the effect of each individual factor, (i.e., the interactions between paired factors had a greater impact on $\mathrm{PM}_{2.5}$ pollution than any single factor). The strongest interaction between factors changed according to the year. For example, $q(\mathrm{PD} \cap \mathrm{IO})$ showed the strongest interaction on five occasions between 2000 and 2017, ranging from 0.59-0.82, indicating that the interaction between PD and IO had the strongest impact on the spatial pattern of $\mathrm{PM}_{2.5}$ pollution. Over the study period, $q(\mathrm{PD} \cap \mathrm{IO}), q(\mathrm{PD} \cap \mathrm{NI})$, and $q(\mathrm{RD} \cap \mathrm{NI})$ had the strongest interactions five, four, and four times, respectively, indicating that population, traffic, and industrial development had increasing interactive effects on the spatial pattern of $\mathrm{PM}_{2.5}$ pollution. 

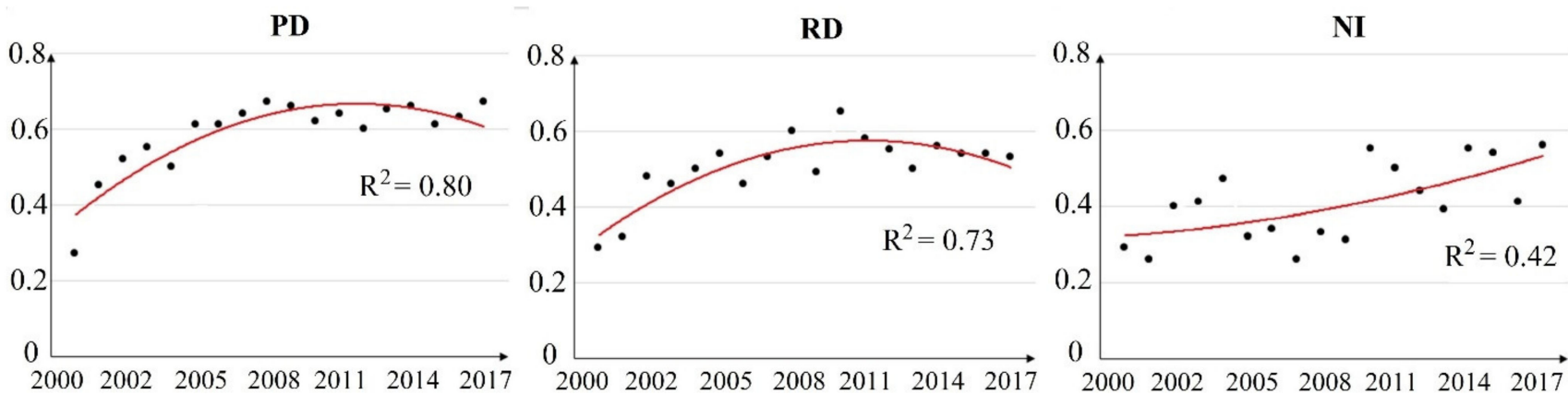

IO
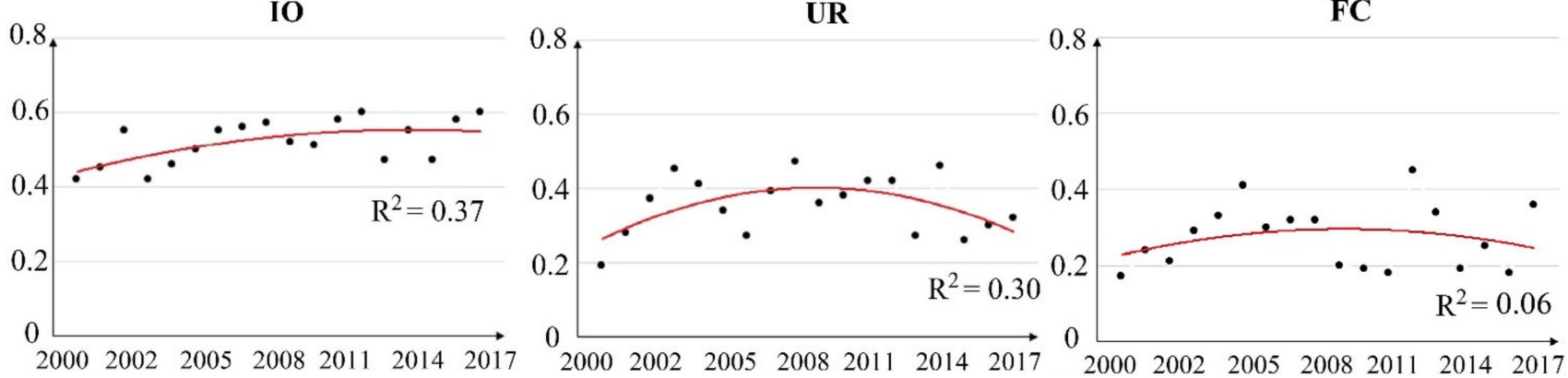

Figure 6. Scatter plots with trend lines of $q$ values for each impact factor from 2000-2017.

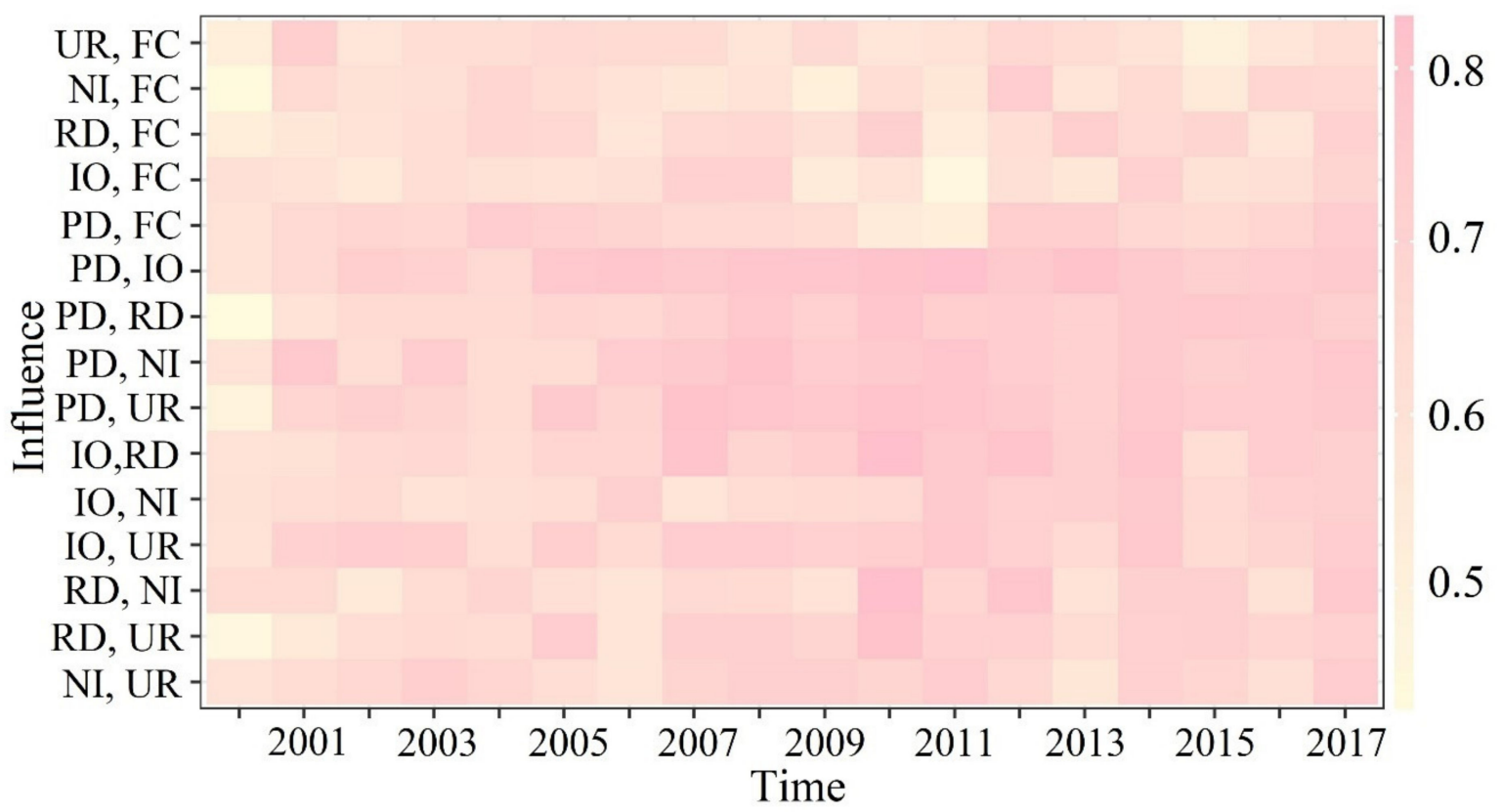

Figure 7. Heatmap of interactive effects from 2000-2017.

Between 2000 and 2017, the scatter plots in Figure 8 show the interactive effects with quadratic polynomials used to fit trend lines and $\mathrm{R}^{2}$ to explore the changing patterns of interactive effects for the driving factors. The interactive effects of $(\mathrm{PD}, \mathrm{RD}),(\mathrm{PD}, \mathrm{IO}),(\mathrm{PD}$, UR), (RD, UR), (IO, RD), (PD, NI), (IO, UR), (RD, FC), (UR, FC), and (NI, UR) essentially showed a tendency to first increase and then decrease (Figure 8). Both (IO, NI), (IO, FC), $(\mathrm{PD}, \mathrm{FC}),(\mathrm{NI}, \mathrm{FC})$, and $(\mathrm{RD}, \mathrm{NI})$ showed long-term increasing trends, meaning that the influence of these factors on $\mathrm{PM}_{2.5}$ concentrations has gradually increased. 

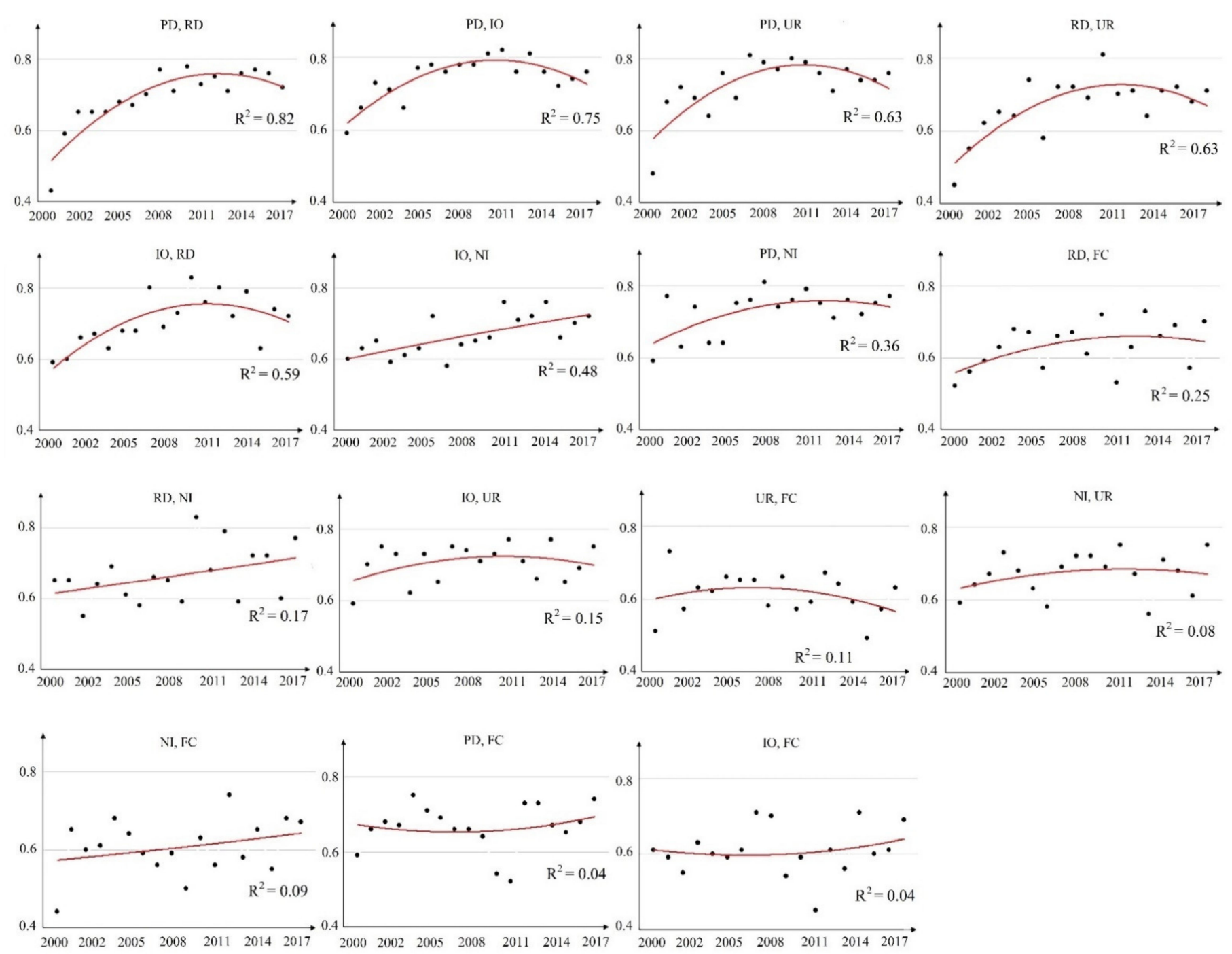

Figure 8. Scatter plots with trend lines of $q$ values for each pair of interactive effects from 2000-2017.

\section{Discussion}

In recent years, problems related to air pollution, especially $\mathrm{PM}_{2.5}$, have become increasingly prominent and have attracted widespread attention. North China, as one of the most densely populated and rapidly urbanizing regions in China, with millions of residents and rapid economic development, has suffered severely from $\mathrm{PM}_{2.5}$ pollution. In this study, a global Moran's I model was used to examine the spatial autocorrelation of $\mathrm{PM}_{2.5}$ concentrations from 2000-2017. A LISA model was utilized to explore the hot and cold spots of $\mathrm{PM}_{2.5}$ concentrations and determinant powers of socioeconomic factors and their interactive impacts on $\mathrm{PM}_{2.5}$ pollution was quantified using GeoDetector. The results indicate that the cities with high pollution risks are mainly distributed in Xinxiang, Kaifeng, Dezhou, Xingtai, and Heze and exhibit significant spatial autocorrelation. Furthermore, the determinant power of PD remained high during the study period, and the interaction between PD and IO was the strongest on five occasions between 2000 and 2017.

In this study, the temporal evolution of $\mathrm{PM}_{2.5}$ concentrations in North China from 2000-2017 was examined and found to have an overall increasing trend. A potential reason for this may be that China has experienced rapid urbanization in recent years, especially in the study area, which is the most concentrated region in terms of industry (e.g., steel, and vehicle use) [32]. It is notable that these industries consume tremendous amounts of fossil fuels and inevitably generate large amounts of industrial emissions. Moreover, in 
the process of urbanization, populations are increasingly concentrated in urban regions, and the demands of transportation and consumption of energy continue to expand with increasing population densities.

Significant and positive spatial autocorrelations existed in the $\mathrm{PM}_{2.5}$ concentrations analyzed here. Hot spots were mainly concentrated in southeastern Hebei, northern Henan, and western Shandong, and specifically in cities such as Xinxiang, Kaifeng, Dezhou, Xingtai, and Heze, to which more attention should be paid. Cold spots were distributed across northern Hebei, southern Henan, and eastern Shandong, in cities such as Qinhuangdao, Chengde, and Yantai.

Many prior studies have demonstrated that socioeconomic factors significantly impact the spatiotemporal patterns of $\mathrm{PM}_{2.5}$ pollution, and it is widely accepted that $\mathrm{PD}$ is a remarkable factor influencing $\mathrm{PM}_{2.5}$ concentrations. Similarly, in this study, the determinant power of PD was the strongest (e.g., $q=0.67$ in 2017), which is widely consistent with the results of previous studies. For example, Ding et al. showed that PD had the strongest impact on $\mathrm{PM}_{2.5}$ concentrations [45], while Lou et al. demonstrated that PD had a critical effect, reflected in the accumulation of $\mathrm{PM}_{2.5}$ by region [46]. Wang et al. also found that $\mathrm{PD}$ exerts a remarkable effect on $\mathrm{PM}_{2.5}$ concentrations [18]. Hinojosa et al. indicated that population was correlated with $\mathrm{PM}_{2.5}$ concentration using data from Mexico City [47]. The results of the current study demonstrate that anthropogenic emissions are the key factors leading to significant increases in $\mathrm{PM}_{2.5}$ concentrations in North China between 2000 and 2017. Anthropogenic emissions are also a fundamental source of secondary aerosols of $\mathrm{PM}_{2.5}$ [48]. Dense populations also consume greater amounts of non-renewable energy, which is considered to be the main source of $\mathrm{PM}_{2.5}$ [28].

In this study, IO was found to have a significant impact on the spatial distribution of $\mathrm{PM}_{2.5}$ concentrations, as has been shown in previous studies. For example, Yang et al. demonstrated that IO had a significant influence on the spatial pattern of $\mathrm{PM}_{2.5}$ concentrations in China [16], and Wang et al. determined that industrial development would increase industrial emissions, resulting in inevitable increases in $\mathrm{PM}_{2.5}$ concentrations [18]. In another study, Zhang et al. suggested that the proportion of secondary industry is the decisive factor in terms of $\mathrm{PM}_{2.5}$ pollution, as industrial activities are the main emission sources, including energy-intensive and high-polluting mining, construction, and manufacturing, which emit exhaust gases and dust into the atmosphere that can form $\mathrm{PM}_{2.5}$ pollution through direct or secondary reactions [19]. Additionally, some regions lack proper management and fail to implement effective energy-saving measures and environmental protection policies. In such regions, $\mathrm{PM}_{2.5}$ emissions have greatly increased. Industry still affects economic and social development in China.

Furthermore, a strong association between $\mathrm{RD}$ and $\mathrm{PM}_{2.5}$ concentrations was found, according to the indicator of traffic conditions $(q=0.53)$, which is consistent with previous research. Yang et al. demonstrated that in China, traffic conditions (depicted by RD) have a significant impact on the spatial patterns of $\mathrm{PM}_{2.5}$ concentrations [16]. Similarly, $\mathrm{Wu}$ et al. determined that traffic conditions, represented by the proportion of road area, exerted a remarkable effect on $\mathrm{PM}_{2.5}$ pollution [21], while Zhang et al. showed that the increasing length of highways would significantly raise the health risks related to $\mathrm{PM}_{2.5}$ in eastern China [19]. Oliveira et al. demonstrated that emissions of light-duty vehicles have impacted on the $\mathrm{PM}_{2.5}$ pollution using data from Brazil [49]. This may occur because rapid urbanization is generally accompanied by a huge demand for buildings, road networks, and other public infrastructure, which directly increase energy consumption and the amount of dust (e.g., emission of vehicles, road and building dust) [21]. Highly accessible roads also indicate increased vehicle usage [50]. Therefore, $\mathrm{RD}$ has a remarkable impact on the accumulation and diffusion of $\mathrm{PM}_{2.5}$.

In assessing the interactions of all tested factors, they all presented non-linear enhanced effects, that is, after interaction, the effect is greater than that of the single factor. Moreover, GeoDetector revealed significantly increasing interactive effects, of which, PD and IO were the strongest on five occasions between 2000 and 2017. Because socioeconomic factors 
are closely related to anthropogenic and industrial emissions, changes over the past few decades to the original ecological environment and human living conditions have increased anthropogenic and industrial emissions that will further promote $\mathrm{PM}_{2.5}$ pollution under the influence of rapidly increasing global urbanization. For instance, socioeconomic activities mainly interact from a spatial perspective, in the ecological environment, and with human settlements and farmland systems, which also strengthen $\mathrm{PM}_{2.5}$ pollution [51]. Therefore, the interaction of socioeconomic factors will amplify the impact of $\mathrm{PM}_{2.5}$ to an extent.

\section{Conclusions, Limitations, and Future Research}

In this study, a global Moran's I was used to examine the spatial autocorrelation of $\mathrm{PM}_{2.5}$ pollution in North China from 2000-2017. Local indicators of spatial association statistics were then used to identify hot and cold spots before the determinant powers of socioeconomic factors and their interactive effects were finally quantified using GeoDetector. The $\mathrm{PM}_{2.5}$ concentrations in the study area exhibited an increasing trend from 2000 to 2017. Additionally, the concentrations showed significant and stronger global spatial autocorrelation. Hot spots were mainly concentrated in the cities of Xinxiang, Kaifeng, Dezhou, Xingtai, and Heze, while cold spots were mainly distributed in the cities of Qinhuangdao and Chengde. PD was shown to have the most decisive influence on the spatial pattern of $\mathrm{PM}_{2.5}$ pollution, and the interactive effect of $\mathrm{PD}$ and IO was the strongest for many times during the period. Between 2000 and 2017, the impacts of PD, RD, UR, and FC trended to first increase and then decrease, while those of NI and IO showed an obviously increasing trend. Finally, the interactive effects of most factors appeared to first increase and then decrease, while the others showed a significant increasing trend. In total, these findings provide a clearer picture of the socioeconomic factors responsible for $\mathrm{PM}_{2.5}$ pollution across cities in North China, which has significant meaning and may be used to guide policy development and remediation measures in the future and mean that more specific control strategies need to be developed for different regions to successfully control and reduce $\mathrm{PM}_{2.5}$ pollution.

Some limitations of this study require mentioning. First, we only considered socioeconomic impact factors in this study, while environmental conditions, such as air temperature and atmospheric humidity, and other pollutant factors, such as $\mathrm{PM}_{10}$, were omitted, in the future research, more attention should be paid to analyze the association between other pollutants and $\mathrm{PM}_{2.5}$ pollution. Second, the association between compositional data and impact factors can be considered in the future research [52]. Third, the data used in our analyses were binned by city (spatially) and by year (temporally), likely introducing some uncertainties. In addition, the accuracy of raw $\mathrm{PM}_{2.5}$ data is considerably high, but it also exists uncertainty in different regions. Thus, data with high spatiotemporal resolution used in further studies might provide high accuracy and efficiency of the quantification of socioeconomic impacts on $\mathrm{PM}_{2.5}$ pollution.

Supplementary Materials: The following are available online at https:/ /www.mdpi.com/article/10 .3390/ijerph18126261/s1, Figure S1: Global Moran's I values of $\mathrm{PM}_{2.5}$ concentrations in 2000, 2005, 2010, and 2017, Figure S2: Frequency of high-high (HH) and low-low (LL) clusters from 2000-2017.

Author Contributions: Conceptualization, Methodology, and Writing-Original draft preparation, X.Z.; Visualization, Investigation, Y.L.; Writing-Reviewing and Editing, Supervision, C.C.; Data curation, Writing-Reviewing and Editing, J.L. All authors have read and agreed to the published version of the manuscript.

Funding: This study was financially supported by the following grants: National Key Research and Development Plan of China (2019YFA0606901); Strategic Priority Research Program of the Chinese Academy of Sciences (XDA23100303); State Key Laboratory of Earth Surface Processes and Resource Ecology (2020-KF-05).

Institutional Review Board Statement: Not applicable.

Informed Consent Statement: Not applicable. 
Data Availability Statement: The data presented in this study are available on request from the corresponding author.

Conflicts of Interest: The authors declare no conflict of interest.

\section{References}

1. Fang, C.; Liu, H.; Li, G. International progress and evaluation on interactive coupling effects between urbanization and the eco-environment. J. Geogr. Sci. 2016, 26, 1081-1116. [CrossRef]

2. Lelieveld, J.; Evans, J.S.; Fnais, M.; Giannadaki, D.; Pozzer, A. The contribution of outdoor air pollution sources to premature mortality on a global scale. Nature 2015, 525, 367-371. [CrossRef] [PubMed]

3. Pyne, S. Air pollution-Small particles add up to big disease risk. Science 2002, 295, 1994. [CrossRef] [PubMed]

4. Kaiser, J. Epidemiology. Mounting evidence indicts fine-particle pollution. Science 2005, 307, 1858-1861. [CrossRef] [PubMed]

5. Li, M.; Zhang, L. Haze in China: Current and future challenges. Environ. Pollut. 2014, 189, 85-86. [CrossRef] [PubMed]

6. Brauer, M.; Amann, M.; Burnett, R.T.; Cohen, A.; Dentener, F.; Ezzati, M.; Henderson, S.B.; Krzyzanowski, M.; Martin, R.V.; Van Dingenen, R.; et al. Exposure assessment for estimation of the global burden of disease attributable to outdoor air pollution. Environ. Sci. Technol. 2012, 46, 652-660. [CrossRef] [PubMed]

7. Guo, J.; Xia, F.; Zhang, Y.; Liu, H.; Li, J.; Lou, M.; He, J.; Yan, Y.; Wang, F.; Min, M.; et al. Impact of diurnal variability and meteorological factors on the $\mathrm{PM}_{2.5}$-AOD relationship: Implications for $\mathrm{PM}_{2.5}$ remote sensing. Environ. Pollut. 2017, 221, 94-104. [CrossRef] [PubMed]

8. Kan, H.; Chen, R.; Tong, S. Ambient air pollution, climate change, and population health in China. Environ. Int. 2012, 42, 10-19. [CrossRef]

9. Siponen, T.; Yli-Tuomi, T.; Aurela, M.; Dufva, H.; Hillamo, R.; Hirvonen, M.R.; Huttunen, K.; Pekkanen, J.; Pennanen, A.; Salonen, I.; et al. Source-specific fine particulate air pollution and systemic inflammation in ischaemic heart disease patients. Occup. Environ. Med. 2015, 72, 277-283. [CrossRef] [PubMed]

10. Suhaimi, N.F.; Jalaludin, J. Biomarker as a research tool in linking exposure to air particles and respiratory health. Biomed Res. Int. 2015, 2015, 962853. [CrossRef] [PubMed]

11. Xie, R.; Sabel, C.E.; Lu, X.; Zhu, W.; Kan, H.; Nielsen, C.P.; Wang, H. Long-term trend and spatial pattern of PM 2.5 induced premature mortality in China. Environ. Int. 2016, 97, 180-186. [CrossRef] [PubMed]

12. Matus, K.; Nam, K.M.; Selin, N.E.; Lamsal, L.N.; Reilly, J.M.; Paltsev, S. Health damages from air pollution in China. Glob. Environ. Change-Human Policy Dimen. 2012, 22, 55-66. [CrossRef]

13. He, J.; Gong, S.; Yu, Y.; Yu, L.; Wu, L.; Mao, H.; Song, C.; Zhao, S.; Liu, H.; Li, X.; et al. Air pollution characteristics and their relation to meteorological conditions during 2014-2015 in major Chinese cities. Environ. Pollut. 2017, 223, 484-496. [CrossRef]

14. Lyu, W.; Li, Y.; Guan, D.; Zhao, H.; Zhang, Q.; Liu, Z. Driving forces of Chinese primary air pollution emissions: An index decomposition analysis. J. Clean Prod. 2016, 133, 136-144. [CrossRef]

15. Dayan, U.; Erel, Y.; Shpund, J.; Kordova, L.; Wanger, A.; Schauer, J.J. The impact of local sources and meteorological factors on nitrogen oxide and particulate matter concentrations: A case study of the Day of Atonement in Israel. Atmos. Environ. 2011, 45, 3325-3332. [CrossRef]

16. Yang, D.; Wang, X.; Xu, J.; Xu, C.; Lu, D.; Ye, C.; Wang, Z.; Bai, L. Quantifying the influence of natural and socioeconomic factors and their interactive impact on $\mathrm{PM}_{2.5}$ pollution in China. Environ. Pollut. 2018, 241, 475-483. [CrossRef] [PubMed]

17. Puentes, R.; Marchant, C.; Leiva, V.; Figueroa-Zuniga, J.I.; Ruggeri, F. Predicting PM 2.5 and $\mathrm{PM}_{10}$ levels during critical episodes management in Santiago, Chile, with a bivariate Birnbaum-Saunders log-linear model. Mathematics 2021, 9, 645. [CrossRef]

18. Wang, Y.; Duan, X.; Wang, L. Spatial-temporal evolution of $\mathrm{PM}_{2.5}$ concentration and its socioeconomic influence factors in Chinese cities in 2014-2017. Int. J. Environ. Res. Public Health 2019, 16, 985. [CrossRef] [PubMed]

19. Zhang, Z.; Shao, C.; Guan, Y.; Xue, C. Socioeconomic factors and regional differences of $\mathrm{PM}_{2.5}$ health risks in China. J. Environ. Manage. 2019, 251, 109564. [CrossRef] [PubMed]

20. Han, L.; Zhou, W.; Li, W.; Li, L. Impact of urbanization level on urban air quality: A case of fine particles $\left(\mathrm{PM}_{2.5}\right)$ in Chinese cities. Environ. Pollut. 2014, 194, 163-170. [CrossRef]

21. Wu, J.; Zheng, H.; Zhe, F.; Xie, W.; Song, J. Study on the relationship between urbanization and fine particulate matter (PM2.5) concentration and its implication in China. J. Clean Prod. 2018, 182, 872-882. [CrossRef]

22. Cavieres, M.F.; Leiva, V.; Marchant, C.; Rojas, F. A methodology for data-driven decision making in the monitoring of particulate matter environmental contamination in Santiago of Chile. Rev. Environ. Contam. Toxicol. 2021, 250, 45-67.

23. Jiang, P.; Yang, J.; Huang, C.; Liu, H. The contribution of socioeconomic factors to $\mathrm{PM}_{2.5}$ pollution in urban China. Environ. Pollut. 2018, 233, 977-985. [CrossRef] [PubMed]

24. Xu, B.; Luo, L.; Lin, B. A dynamic analysis of air pollution emissions in China: Evidence from nonparametric additive regression models. Ecol. Indic. 2016, 63, 346-358. [CrossRef]

25. Du, Y.; Wan, Q.; Liu, H.; Liu, H.; Kapsar, K.; Peng, J. How does urbanization influence PM $_{2.5}$ concentrations? Perspective of spillover effect of multi-dimensional urbanization impact. J. Clean Prod. 2019, 220, 974-983. [CrossRef]

26. Li, J.; Han, X.; Jin, M.; Zhang, X.; Wang, S. Globally analysing spatiotemporal trends of anthropogenic $\mathrm{PM}_{2.5}$ concentration and population's $\mathrm{PM}_{2.5}$ exposure from 1998 to 2016. Environ. Int. 2019, 128, 46-62. [CrossRef]

27. Zhang, R.; Wang, G.; Guo, S.; Zarnora, M.L.; Ying, Q.; Lin, Y.; Wang, W.; Hu, M.; Wang, Y. Formation of urban fine particulate matter. Chem. Rev. 2015, 115, 3803-3855. [CrossRef] [PubMed] 
28. Salim, R.A.; Shafiei, S. Urbanization and renewable and non-renewable energy consumption in OECD countries: An empirical analysis. Econ. Model. 2014, 38, 581-591. [CrossRef]

29. Hu, X.; Waller, L.A.; Al-Hamdan, M.Z.; Crosson, W.L.; Estes, M.G., Jr.; Estes, S.M.; Quattrochi, D.A.; Sarnat, J.A.; Liu, Y. Estimating ground-level $\mathrm{PM}_{2.5}$ concentrations in the southeastern US using geographically weighted regression. Environ. Res. 2013, 121, 1-10. [CrossRef] [PubMed]

30. Wu, X.; Cheng, C.; Zurita-Milla, R.; Song, C. An overview of clustering methods for geo-referenced time series: From one-way clustering to co- and tri-clustering. Int. J. Geogr. Inf. Sci. 2020, 34, 1822-1848. [CrossRef]

31. Zhang, Y.L.; Cao, F. Fine particulate matter $\left(\mathrm{PM}_{2.5}\right)$ in China at a city level. Sci. Rep. 2015, 5, 14884. [CrossRef] [PubMed]

32. Zhao, B.; Wang, P.; Ma, J.Z.; Zhu, S.; Pozzer, A.; Li, W. A high-resolution emission inventory of primary pollutants for the Huabei region, China. Atmos. Chem. Phys. 2012, 12, 481-501. [CrossRef]

33. U.S. Atmospheric Composition Analysis Group of Dalhousie University. Available online: https://sites.wustl.edu/acag/ (accessed on 15 March 2020).

34. Van Donkelaar, A.; Martin, R.V.; Brauer, M.; Hsu, N.C.; Kahn, R.A.; Levy, R.C.; Lyapustin, A.; Sayer, A.M.; Winker, D.M. Global estimates of fine particulate matter using a combined geophysical-statistical method with information from satellites, models, and monitors. Environ. Sci. Technol. 2016, 50, 3762-3772. [CrossRef] [PubMed]

35. Zhang, X.X.; Gu, X.C.; Cheng, C.X.; Yang, D.Y. Spatiotemporal heterogeneity of $\mathrm{PM}_{2.5}$ and its relationship with urbanization in North China from 2000 to 2017. Sci. Total Environ. 2020, 744, 140925. [CrossRef]

36. Open Street Map. Available online: https:/ / www.openstreetmap.org (accessed on 20 May 2020).

37. Moran, P.A.P. Notes on continuous stochastic phenomena. Biometrika 1950, 37, 17-23. [CrossRef] [PubMed]

38. Anselin, L. Local indicators of spatial association-LISA. Geogr. Anal. 1995, 27, 93-115. [CrossRef]

39. Wang, J.F.; Li, X.H.; Christakos, G.; Liao, Y.L.; Zhang, T.; Gu, X.; Zheng, X.Y. Geographical Detectors-based health risk assessment and its application in the neural tube defects study of the Heshun region, China. Int. J. Geogr. Inf. Sci. 2010, 24, 107-127. [CrossRef]

40. Wang, J.F.; Xu, C.D. Geodetector: Principle and prospective. Acta Geogr. Sinica 2017, 72, 116-134.

41. Wang, J.F.; Zhang, T.L.; Fu, B.J. A measure of spatial stratified heterogeneity. Ecol. Indic. 2016, 67, 250-256. [CrossRef]

42. Zhang, X.X.; Xu, C.D.; Xiao, G.X. Spatial heterogeneity of the association between temperature and hand, foot, and mouth disease risk in metropolitan and other areas. Sci. Total Environ. 2020, 713, 136623. [CrossRef] [PubMed]

43. Zhang, X.; Nie, J.; Cheng, C.; Xu, C.; Zhou, L.; Shen, S.; Pei, Y. Natural and socioeconomic factors and their interactive effects on house collapse caused by typhoon Mangkhut. Int. J. Disaster Risk Sci. 2021, 12, 121-130. [CrossRef]

44. Wang, L.; Xu, C.; Wang, J.; Qiao, J.; Yan, M.; Zhu, Q. Spatiotemporal heterogeneity and its determinants of COVID-19 transmission in typical labor export provinces of China. BMC Infect. Dis. 2021, 21, 242. [CrossRef] [PubMed]

45. Ding, Y.; Zhang, M.; Qian, X.; Li, C.; Chen, S.; Wang, W. Using the geographical detector technique to explore the impact of socioeconomic factors on PM2.5 concentrations in China. J. Clean Prod. 2019, 211, 1480-1490. [CrossRef]

46. Lou, C.R.; Liu, H.Y.; Li, Y.F.; Li, Y.L. Socioeconomic drivers of $\mathrm{PM}_{2.5}$ in the accumulation phase of air pollution episodes in the Yangtze River Delta of China. Int. J. Environ. Res. Public Health 2016, 13, 928. [CrossRef]

47. Hinojosa-Balino, I.; Infante-Vazquez, O.; Vallejo, M. Distribution of $\mathrm{PM}_{2.5}$ Air pollution in Mexico City: Spatial analysis with land-use regression model. Appl. Sci. Basel 2019, 9, 2936. [CrossRef]

48. Liang, C.S.; Duan, F.K.; He, K.B.; Ma, Y.L. Review on recent progress in observations, source identifications and countermeasures of $\mathrm{PM}_{2.5}$. Environ. Int. 2016, 86, 150-170. [CrossRef] [PubMed]

49. Oliveira., R.L.; Loyola, J.; Minho, A.S.; Quiterio, S.L.; Azevedo, D.D.A.; Arbilla, G. PM 2.5 -bound polycyclic aromatic hydrocarbons in an area of Rio de Janeiro, Brazil impacted by emissions of Light-Duty vehicles fueled by ethanol-blended gasoline. Bull. Environ. Contam. Toxicol. 2014, 93, 781-786. [CrossRef] [PubMed]

50. Zhou, C.; Chen, J.; Wang, S. Examining the effects of socioeconomic development on fine particulate matter $\left(\mathrm{PM}_{2.5}\right)$ in $\mathrm{China}$ 's cities using spatial regression and the geographical detector technique. Sci. Total Environ. 2018, 619, 436-445. [CrossRef] [PubMed]

51. Gu, B.; Sutton, M.A.; Chang, S.X.; Ge, Y.; Chang, J. Agricultural ammonia emissions contribute to China's urban air pollution. Front. Ecol. Environ. 2014, 12, 265-266. [CrossRef]

52. Pawlowsky-Glahn, V.; Egozcue, J.J.; Tolosana-Delgado, R. Modeling and Analysis of Compositional Data; Wiley: New York, NY, USA, 2015. 